\title{
IMAGEN CITOLÓGICA VAGINAL DURANTE EL CICLO OVÁRICO EN MONOS NOCTURNOS Aotus nancymae y A. vociferans
}

\author{
Patricia Rios M. ${ }^{1}$, Luisa Echevarria C. ${ }^{2}$, Gilberto Santillán A. ${ }^{2}$ \\ y Hugo Gálvez C. $^{3}$
}

\section{Alsiract}

Changes in vaginal cytology during the ovarian cycle of 11 owl monkeys (Aotus nancymae and $A$. vociferans) were examined through analysis of vaginal smears with May grüwal - Giemsa stain, collected every second day during a 16 day period. Serum progesterone levels were determined by radioinmunoassay on four occasions over a 14 day period. Changes in the proportions of epithelial cells related to ovarian function were observed in 8 of 10 females. Squamous cells quickly increased to $70 \%$ while serum progesterone levels were basal. Vaginal cytology from a pregnant female is also reported. Key words: Vaginal cytology, ovarian cycle, Aotus.

\section{Resumen}

Un registro interdiario de los cambios de la imagen citológica vaginal durante el desarrollo del ciclo ovárico, fue llevado a cabo en 11 monos hembras adultas pertenecientes al género Aotus. Los frotices obtenidos durante 16 días fueron teñidos con coloración May Grüwal - Giemsa para su lectura. Durante este período se midieron niveles de progesterona sérica, cada cuatro días mediante Radioinmunoensayo, obteniéndose perfiles de dicha hormona durante el ciclo ovárico. Los cambios en la proporción de las células epiteliales se dieron por períodos definidos; coincidiendo con el estado funcional del ovario. Las proporciones de células exfoliativas superficiales se elevaron de manera acelerada hasta en un $70 \%$, cuando los niveles séricos de progesterona se mantuvieron basales. Se concluye que la imagen citológica del frotis vaginal es indicadora del estado reproductivo.

Palabras clave: Citología vaginal, ciclo ovárico, Aotus.

\section{Imbuttestin}

Actualmente el Instituto Veterinario de Investigaciones Tropicales y de Altura (IVITA) en su Estación del Trópico de Iquitos, viene estudiando Primates No Hu-

\footnotetext{
$1 \quad$ Práctica privada

2 Laboratorio de Reproducción - FMV UNMSM.d170014@unmsm.edu.pe

3 EE - Iquitos - IVITA - FMV - UNMSM.
}

manos tanto en su medio natural como en cautiverio con fines de lograr una utilización renovable de dichos recursos.

En línea con lo anterior los estudios reproductivos son del mayor interés y dentro de esta orientación contar con herramientas como el uso de la citología vaginal para obtener información sobre el estado reproductivo de la hembra, sin dañar o causar molestias en el animal, sería de gran utilidad. 
La presente investigación tiene como objetivos registrar los cambios en la imagen colpocitológica durante el desarrollo del ciclo reproductivo de la mona y determinar, de esta manera, si esta especie presenta una imagen citológica similar o diferente a la de otras especies.

\section{Materules y Mrtutos}

Los animales utilizados provinieron de la colonia de reproductores del Centro de Reproducción y Conservación de Primates No Humanos de Iquitos (CRCP), del Instituto Veterinario de Investigaciones Tropicales y de Altura (IVITA).

Se usaron seis hembras adultas de la especie Aotus vociferans y cinco de Aotus nancymae de ocho o más años de edad y un historial de actividad reproductiva conocida (más de tres crías viables); la última cría con más de cuatro meses de edad.

Cada hembra fue alojada en celdas de $1 \times 1 \times 2 \mathrm{~m}$, que contaban con una pequeña caja superpuesta que funcionó como dormidero y a su vez jaula de atrape con la siguiente dimensión $40 \times 30 \times 30 \mathrm{~cm}$. Durante el estudio las hembras estuvieron separadas del macho, tal como lo recomienda Ruiz y Colillas (1981).

Los individuos fueron alimentados dos veces al día con galletas especialmente preparadas (Montoya, et al. 1995) y medio plátano por animal, el agua fue suministrado ad libitum. La dieta se complementó con una papilla consistente en: harina de galleta (36 g), plátano $(100 \mathrm{~g})$, Cerelac $(5 \mathrm{~g})$, además se les proporcionó azúcar en el agua ( $10 \mathrm{~g}$ en $225 \mathrm{ml}$ ).

Los pesos corporales fueron registrados semanalmente.

Las muestras vaginales se tomaron en forma interdiaria y por un período de 16 días; abarcando un ciclo ovárico (Bonney y
Dixon, 1979; Díxon, 1994; Richter, 1984). Para ello se utilizó un hisopo estéril de ocho $\mathrm{cm}$. de longitud. Todos los animales fueron muestreados en las mismas fechas. Con la ayuda de un operario se mantuvo firme al animal, en posición de cúbito dorsal, sosteniendo su cabeza con una mano y con la otra el vientre. A continuación, se introdujo una torunda mojada con suero fisiológico por la vulva, en dirección craneodorsal; la cual se giró levemente con suavidad y se retiró evitando que sus bordes toquen los labios vulvares. La longitud del hisopo fue de un $\mathrm{cm}$.

Los extendidos se realizaron girando la torunda sobre el portaobjeto y por duplicado. Luego de la extensión, las muestras fueron fijadas con alcohol - metanol (sumersión por 45 segundos) y posteriormente teñidas en el laboratorio. La coloración utilizada fue May Grüwal - Giemsa (Piñeiro y Gorraiz, 1995) cuya técnica consistió en teñido con May - Grüwal por tres minutos, enjuague con agua destilada por un minuto y luego teñido con Giemsa por 15 minutos.

Una de las muestras no fue fijada, sino coloreada inmediatamente en el laboratorio con colorantes May Grüwal Giemsa, haciéndose uso de la técnica antes indicada.

Las muestras de sangre $(2 \mathrm{~cm}$.) se obtuvieron por punción directa de la vena femoral con aguja \# 21 y por goteo directo al tubo. Los animales fueron previamente anestesiados con ketamina $(10 \mathrm{mg} / \mathrm{Kg}) . \mathrm{La}$ sangre obtenida fue refrigerada por un día para obtener el suero. Posteriormente este suero fue conservado a $-10^{\circ} \mathrm{C}$ antes de ser procesado para determinar progesterona y estradiol utilizando los kits DPC Estradiol y Progesterona. El muestreo se realizó durante las primeras horas de la mañana (Dixon, 1981), una vez cada cuatro días (con la excepción del último muestreo que se realizó luego de cinco días de intervalo); comprendiendo un período total de 14 días. El número de muestras obtenidas fue de cuatro por individuo. 
Las muestras fueron examinadas microscópicamente para determinar el tipo de células superficiales (nucleadas o anucleadas), intermedias y parabasales.

En los extendidos se contaron 100 células, ubicándose primero la zona con mayor presencia celular a un aumento de 160; a continuación, se procedía a identificar las células con un aumento de $640 \mathrm{X}$, avanzando progresivamente (hacia arriba - lateral abajo) hasta completar los 100 elementos celulares.

La presencia de leucocitos fue anotada al encontrarse uno o más neutrófilos en el campo.

Las observaciones por lámina / día fueron clasificadas, de acuerdo a los estándares suscritos por Mateu (1978) y Schnell (1975).

\section{Resultados}

Los resultados de la lectura del frotís se resumen en el Cuadro 1. La imagen de la citología vaginal exhibida en los frotices permitió una identificación y cuantificación de las diversas formas celulares. Debe destacarse que la técnica combinada fijación + teñido confirió una mayor nitidez a la imagen; especialmente de las células superficiales e intermedias superiores.

Resumiendo la información anterior podemos caracterizar las dos fases ciclo ovárico como sigue:

\section{Fase Folicular}

Elevación acelerada de células superficiales a manera de grupos aislados, cuya presencia pasa de un $30 \%$ cuatro días posteriores a la manifestación de niveles basales de progesterona, hasta llegar a $70 \%$ al final de la fase folicular. También se puede apreciar la presencia en algunos casos, de célu- las parabasales e intermedias inferiores dispersas en formaciones aisladas tipo cúmulo. Se destaca además, que el frotís obtenido se mantuvo siempre consistentemente espeso y sucio e incluso grumoso por la presencia de moco abundante.

\section{Fase Luteínica}

Aquí la casi totalidad de las células presentes son de la capa intermedia, siendo las intermedias inferiores con su núcleo grande característico, las de mayor presentación. En el frotís las células superficiales disminuyeron drásticamente, aunque en algunas láminas, estas células pueden ser vistas sin exceder el $18 \%$ del total celular.

Las células parabasales tienden a acompañar el cuadro, presentándose de forma indiferente ya sea hacia el inicio o el final de esta fase.

Los leucocitos fueron observados indistintamente a través de todo el ciclo, alcanzando un porcentaje bajo que aumentó levemente durante la fase luteal.

Sólo 8 de 10 hembras mostraron cambios citológicos compatibles con un ciclo ovárico, ya que la mona \# T - 197 estaba en estado de gestación temprana durante el muestreo.

\section{Discusión}

La imagen de las células exfoliativas vaginales encontrada en los animales estudiados, es similar a la observada por Mateu y Aragones (1978), Pérez (1995), Schnell, (1975) y Yen (1993) quienes describen estudios realizados en la mujer; así como por Bank (1992), Gobello (1997), Kirk (1987), Kraft (1998) y Piñeiro (1995); investigadores de diversas especies domésticas. Es de resaltar que la imagen coincide también con la reportada por Jarosz y Iuelh (1977) para el Primate del genero Saimiri. 
Cuadro 1. Cambios Citológicos Vaginales ${ }^{1}$ en monas según días del ciclo ovárico

\begin{tabular}{cccccccccc}
\hline \multirow{2}{*}{ Hembra } & \multicolumn{10}{c}{ Días del ciclo ovárico } \\
\cline { 2 - 10 } & 0 & 2 & 4 & 6 & 8 & 10 & 12 & 14 & 16 \\
\hline 2614 & 1.1 & 2.3 & 3.2 & 3.4 & 4.3 & 2.3 & 1.2 & 2.3 & 2.2 \\
209 & 1.2 & 2.2 & -- & 3.2 & 3.4 & 4.3 & 2.2 & 1.2 & 1.1 \\
T 73 & 3.3 & 2.3 & 2.3 & 2.3 & 2.2 & 3.2 & 3.3 & - & 2.3 \\
T 512 & 2.3 & 1.2 & 2.1 & 3.3 & 2.3 & 2.3 & 2.2 & 2.3 & 1.2 \\
2491 & 1.1 & 2.3 & 3.4 & 4.3 & 3.4 & 3.2 & 2.3 & 2.1 & 1.1 \\
T 76 & 1.1 & 1.2 & 3.2 & 3.4 & 3.4 & 2.3 & 2.2 & 1.1 & 1.2 \\
981 & 1.1 & 2.1 & 3.4 & 2.1 & 1.2 & 2.2 & 1.1 & 1.1 & 1.1 \\
T 217 & 3.3 & 1.2 & 1.1 & 2.3 & -- & 2.3 & 3,2 & 3.2 & 3.2 \\
T 197 & 2.3 & 2.2 & 2.2 & 2.3 & 2.1 & 2.1 & 2.2 & 2.2 & 2.2 \\
T 190 & 4.3 & 3.4 & 2.2 & 2.2 & 3.4 & -- & 2.3 & 2.3 & 3.2 \\
991 & 1.2 & 1.1 & 4.4 & 3.2 & -- & 1.2 & 1.1 & 1.2 & 2.1 \\
\hline
\end{tabular}

--: Abundantes secreciones, pocas células

1 Lós números representan lo siguiente:

\begin{tabular}{clcl}
\hline Clasificación & \multicolumn{1}{c}{ Características } & Clasificación & \multicolumn{1}{c}{ Características } \\
\hline 4,4 & $\begin{array}{l}\text { Exclusivamente células } \\
\text { superficiales }\end{array}$ & 2,3 & $\begin{array}{l}\text { Predomino de células } \\
\text { intermedias inferiores, menos } \\
\text { intermedias superiores }\end{array}$ \\
4,3 & $\begin{array}{l}\text { Predominio de células } \\
\text { superficiales, menos } \\
\text { intermedias superiores. }\end{array}$ & 2,2 & $\begin{array}{l}\text { Exclusivamente células } \\
\text { intermedias inferiores }\end{array}$ \\
3,4 & $\begin{array}{l}\text { Predominio de células } \\
\text { intermedias superiores, } \\
\text { menos superficiales }\end{array}$ & 2,1 & $\begin{array}{l}\text { Predominio de células } \\
\text { intermedias inferiores, menos } \\
\text { parabasales. }\end{array}$ \\
3,3 & $\begin{array}{l}\text { Exclusivamente células } \\
\text { intermedias superiores }\end{array}$ & 1,2 & $\begin{array}{l}\text { Predominio células parabasales, } \\
\text { menos intermedias }\end{array}$ \\
3,2 & $\begin{array}{l}\text { Predominio de células } \\
\text { intermedias superiores, } \\
\text { menos intermedias } \\
\text { inferiores }\end{array}$ & 1,1 & $\begin{array}{l}\text { Exclusivamente células } \\
\text { parabasales. }\end{array}$ \\
\hline
\end{tabular}

Durante la fase folicular que tiene una duración de seis días (Bonney, 1979; Díxon, 1994; Richter, 1984) se encontró un aumento paulatino de células cornificadas hasta un 70 $\%$. Este aumento de células concuerda con lo sustentado por Bank (1992), Kirk (1987), Kraft (1998), Montalvo (1976), Pérez (1995) y Schnell (1975) quienes informan que el nivel de células acidófilas se incrementa paulatinamente dos o tres días posteriores al inicio del incremento de estradiol.
Durante la fase luteal, que tiene una duración de 10 días (Bonney y Dixson, 1979; Díxson, 1994; Richter y Hemrickson, 1984), las células superficiales decrecen rápidamente, predominando las células intermedias inferiores y parabasales, también descritas por Bank (1992); Kirk (1987); Kraft (1998); Gobello (1997); Mateu (1978); Pérez (1995); Piñeiro (1995); Schnell (1975) y Yen (1993). Hay que destacar que la presencia de leucocitos no es un signo exclusivo de esta 
etapa, como lo indican Bank (1992); Kraft (1998) y Piñeiro (1995); si no que suelen mantenerse indistintamente durante el ciclo. Ruiz (1981) atribuy6 a la delgadez del epitelio vaginal de esta especie, la difusión de las células blancas a través de todo el ciclo.

Nuestros resultados difieren de los obtenidos por Bonney (1980) en la hembra Aotus, quien concluyó que los frótices vaginales no se constituían en reflejo de la actividad ovárica; indicando que en todos los frotices examinados se encontraron las diversas formas celulares. Este estudio resalta la importancia de determinar la proporción celular durante los estadíos ováricos, ya que la relación numérica de las diversas células tiende a variar entre una y otra fase.

El espécimen T 197 presentó niveles serológicos de progesterona muy altos que nunca llegaron a descender, esto sugirió un estado de gestación en desarrollo, lo cual posteriormente fue corroborado con el parto. En este caso el cuadro observado es completamente diferente al manifestado por los otros monos. Aquí las células parabasales, tienden a constituir la estructura celular primaria. Las células intermedias superiores e inferiores también fueron observadas al inicio disminuyendo en número a medida que progresaba el muestreo, sin que su presencia llegara a ser nula.

\section{Literitura Chat}

1. Bank. W. 1992. Histología veterinaria aplicada. p.702-703. Editorial Manual Moderno.

2. Berek, J. y P. Billard. 1997. ginecología de novak. 12va edición mc graw. hill. interamericana.pg:160-172.

3. Bonney, R.C. y A.F. Dixon. 1980. plasma concentrations of estradiol $17 \mathrm{~b}$, oestrone, progesterone and testosterone during the ovarian cycle of the owl monkey. in journal of reproduction and fertility. 60: 101-108.

4. Bonney, R.C. y A.F. Dixon. 1979. Cyclic changes in the circulating and urinary levels of ovarian steroids in the adult female owl monkey. in journal of reproduction and fertility. 56:271-280.

5. Dixson, A. 1994. Reproductive biology of the owl monkey. from: aotus: the owl monkey. Baer, Janet. Ap. p.117-131.

6. Dixson, A. 1981. Diurnal variations in plasma testosterone in a male nocturnal primate. In: journal of reproduction and fertility. 62:83-86.

7. Gobello, M.C. 1997. Aplicaciones clínicas de la citología vaginal. en revista ciencia veterinaria. Volumen 13:72.

8. Jarosz, S. y J. Iuelh. 1977. Vaginal cytology and gestation in the squirrel monkey. in biology and reproduction 16:97-103.

9. Kirk, R. W. 1987. Current veterinary therapy.p.1276-1279. Editorial Saunders.

10. Kraft, H. 1998. Métodos de laboratorio clínico en veterinaria de mamíferos domésticos. Editorial Acribia S.A.p:234-237.

11. Mateu, J. y M. Aragones.1978. Atlas de colposcopía. p.120. Ed. Jims Barcelona - España.

12. Montalvo, L. 1976. Citología vaginal, endocervical y endometrial hormonal y maligna. 2da. Edición. p.180. Ed. Científico - Médica.

13. Montoya, E. y J. Moro y A. Gozalo. 1995. Reproducción de aotus vociferans (primates cebidae) en cautiverio. En. Rev. Inv. Pec. IVITA.( Perú). 7 (2). p. 122

14. Pérez, E. 1995. Infertilidad, esterilidad y endocrinología de la reproducción. Segunda edición. p.25-40; 149-159. Ciencia y cultura latinoamericana. México.

15. Piñeiro, C. y J.M. Gorraiz. 1995. Green book de veterinaria. p.50 - 55.

16. Richter B., N. Lehner y R. Henrickson. 1984. Primates cap. 11. p. 324

17. Ruiz, J. y O. Colillas. 1981. Ciclo ovárico del marmoset común. Centro Argentino de Primates, Conicet, Corrientes. Acta physiol. Latinoam.32:59-61.

18. Schnell, J. 1975. Citología y microbiología de la vagina. S. kanger, basel. Alemania. pp 100.

19. Yen, J. 1993. Endocrinología de la reproducción. 3era edición. p.298-319. Editorial Médica Panamericana. 